\section{Making sense of the inferno}

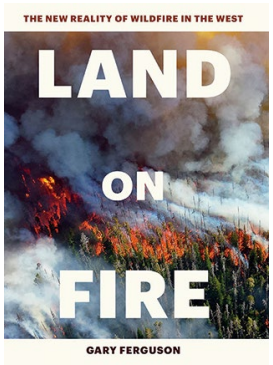

Land on Fire: The

New Reality of Wildfire in the West

By Gary Ferguson

TIMBER PRESS: 2017. 212 PP. $€ 21.99$
$\mathrm{R}$ ecent headlines from around the world can inform us about the presence and status of wildfires, but offer little in the way of historic, geographic or even scientific context about how these fires shape the world we live in. Wildfires that can tear through forests and brush lands led to the creation of one of the most famous icons in American history, Smokey Bear, and dominate the imagination of millions who think that one fire is the same as any other. However, as Gary Ferguson explains in Land on Fire, these events are influenced by a number of factors that interact with each other to create either a small-scale clearing burn or a region-sized conflagration.

While the discussion of flammability thresholds and fuel moisture are critical to analysing fire risk (and it should be noted that Ferguson makes the science of fire accessible to non-experts), two factors matter more than any other when it comes to this era of ever-growing wildfires: humans and climate change. Nine out of ten wildfires are started by humans. While intentional clearing-fires are important and essential to keep larger, catastrophic fires from happening, climate change is rendering the entire American west, as well as many other regions around the world, into an almost permanently flammable zone extending the fire season, increasing the number of pests killing trees and making it more difficult to get water to even fight the fires once they start.

These factors not only lead to an increase in fire, but also will inexorably lead to an increase in devastation and costs for the rest of society. Those on the fire line are facing the brunt of escalating fire risks; the 22 'hotshots' who died in Arizona in the Yarnell Hill disaster of 2013 were not the first group of forest fire fighters to die in the line of duty, and are highly unlikely to be the last. As humans and fire encroach on each other's territory, these men and women will be called on for longer stretches of time, and possibly without an attendant increase in money to back them up. The new normal that Ferguson describes is one of fire and destruction on every horizon, as far as the eye can see.

Reviewed by Ryan Scarrow

Published online: 3 May 2018 https://doi.org/10.1038/s41477-018-0147-4 